Char act erizat i on of mur i ne T-cel I epi topes on mycobact er i al DNA- bi ndi ng prot ei n 1 ( MDP1) usi ng DNA vacci nat i on

\begin{tabular}{|l|l|}
\hline 著者 & $\begin{array}{l}\text { Suzuki Dai suke, Nagat a Toshi, Nat sumbt o } \\
\text { Sohki chi, Nat sunnt o Nakot o, Tsuj i mur a Kuni o, } \\
\text { Koi de Yuki o }\end{array}$ \\
\hline $\begin{array}{l}\text { j our nal or } \\
\text { publ i cat i on ti tl e }\end{array}$ & Vacci ne \\
\hline vol une & 28 \\
\hline nunber & 8 \\
\hline page r ange & $2020-2025$ \\
\hline year & $2010-02-23$ \\
\hline URL & ht t p: //hdl . handl e. net /10271/2406 \\
\hline
\end{tabular}




\title{
Characterization of murine T-cell epitopes on mycobacterial DNA-binding protein 1 (MDP1) using DNA vaccination
}

\author{
Daisuke Suzuki $^{\mathrm{a},}{ }^{*}$, Toshi Nagata ${ }^{\mathrm{b}}$, Sohkichi Matsumoto ${ }^{\mathrm{c}}$, Makoto Matsumoto ${ }^{\mathrm{d}}$, \\ Kunio Tsujimura ${ }^{\mathrm{e}}$, Yukio Koide \\ ${ }^{a} 3 r d$ Department of Internal Medicine, ${ }^{b}$ Department of Health Science, \\ Hamamatsu University School of Medicine, 1-20-1 Higashi-ku, Handa-yama, Hamamatsu, Japan \\ ${ }^{c}$ Department of Host Defense, Osaka City University Graduate School of Medicine, Osaka, Japan \\ ${ }^{d}$ Otsuka Pharmaceutical Co., Ltd., Kagasuno 463-10 Kawauchi-cho, Tokushima, Japan \\ ${ }^{e}$ Department of Infectious Diseases, \\ Hamamatsu University School of Medicine, 1-20-1 Higashi-ku, Handa-yama, Hamamatsu, Japan
}

*Corresponding author. Tel. and fax: +81534352332.

E-mail address: zonx@hama-med.ac.jp (D. Suzuki) 


\begin{abstract}
Mycobacterial DNA binding protein 1 (MDP1) is a major protein antigen in mycobacteria and induces protective immunity against Mycobacterium tuberculosis infection in mice. In this study we determined murine T-cell epitopes on MDP1 with MDP1 DNA immunization in mice. We analyzed interferon- $\gamma$ production from the MDP1 DNA-immune splenocytes in response to 20-mer overlapping peptides covering MDP1 protein. We identified several CD4+ T-cell epitopes in three inbred mouse strains and one CD8+ T-cell epitope in C57BL/6 mice. These T-cell epitopes would be feasible for analysis of the role of MDP1-specific T cells in protective immunity and for future vaccine design against M. tuberculosis infection.
\end{abstract}

Key words: DNA immunization; T-cell epitope; Mycobacterium tuberculosis 


\section{Introduction}

Tuberculosis (TB) has been one of the most serious infectious diseases in the world. There were estimated 9.2 million new causes and 1.7 million deaths from TB in 2006 [1]. One third of people in the world have been infected with Mycobacterium tuberculosis (Mtb), the causative agent of TB. Multidrug-resistant TB and co-infection of Mtb with human immunodeficiency virus are recent problems [1].

The only TB vaccine currently available is the attenuated Mycobacterium bovis strain Bacillus Calmette-Guérin (BCG). Although the BCG vaccine is the oldest and the most widely used vaccine [2], the effect of which has been questioned for preventing pulmonary TB in adults [3] and also to wane with time since vaccination [4]. Therefore, the improved vaccine is an urgent need against TB [5].

Cell-mediated immunity plays a pivotal role in the control of Mtb infection $[6,7]$. There is mounting evidence that CD4+ type 1 helper T (Th1) cells are involved in the development of resistance to the disease, primarily through the production of macrophage-activating cytokines such as interferon (IFN)- $\gamma$ and tumor necrosis factor (TNF)- $\alpha$. In addition, CD8+ cytotoxic T lymphocytes (CTL) contribute to disease resistance since susceptibility to Mtb is increased in mice with deficient in CD8+ T cells [8].

Identification of protective antigens is a crucial step to develop effective vaccines against TB. Many protective antigen candidates have been reported. They include, secreted and membrane-bound proteins, virulence factors such as PE/PPE or EsX, or proteins expressed in host macrophages $[9,10]$. Since Mtb causes both acute disease and asymptomatic latent infection, antigens expressed in the dormant state have been also focused as target antigens for therapeutic vaccination of latent tuberculosis. Persisting baccili resides within the hypoxic environment of the lung granulomas. Therefore, it is generally accepted that low oxygen tension induces 
dormancy program of Mtb. Proteins expressed at the dormant stage include, two-component response regulator, dormancy survival regulator (DosR; Rv3133c) [11] and at least 20 other proteins encoded by the DosR regulon [12].

MDP1 is a major cellular protein of slow growers of mycobacteria [13]. The cellular content of MDP1 in mycobacterial cells increases at stationary and low-oxygen tension-induced non-replicating dormant phases [14]. MDP1 is a histone-like DNA-binding protein binding to GC-rich DNA and considered to control gene expression in mycobacteria [13, 15]. MDP1 has an activity to suppress the growth rate of bacteria presumably by inhibiting macromolecular biosyntheses [16]. Recently, Lewin and colleagues [17] showed that reduction of MDP1 expression by antisence plasmid increased the growth of BCG in both broth culture and macrophages. They showed that the antisense DNA inhibited the aggregation of BCG and reduced expression of several proteins in hypoxic condition as well, suggesting a role of MDP1 in regulation of gene expression in dormant baccili. In addition to the role in the cytoplasm, MDP1 is exported by unknown mechanism to the cell wall and control the mycolic acid transfer [18] and mycobacterial adherence to lung epithelial cells [19]. Thus, MDP1 is a pleiotropic protein which has strong impacts on the mycobacterial virulence.

MDP1 has been also reported to be one of immunocompetent antigens. Prabhakar and colleagues [20] identified this protein as an immunodominant protein in human healthy contacts with TB patients through T-cell blot assay. They designated this protein as histone-like protein of Mtb (HLP $\mathrm{Mt}_{\mathrm{Mt}}$, which is the same molecule as MDP1. Matsumoto and colleagues [21] found that CpG DNA enhances immunogenicity of MDP1, such as productivity of TNF- $\alpha$ and IL-6 from mouse macrophages. They showed that co-immunization of BALB/c and $\mathrm{C} 3 \mathrm{H} / \mathrm{He}$ mice with MDP1 and Mtb DNA elicited IFN- $\gamma$ production specific for this protein and caused reduction of the bacterial burden following Mtb challenge [21].

DNA vaccination with gene gun bombardment is a reliable method to induce reproducible 
T-cell responses [22] and has been used for identification of T-cell epitopes of Mtb antigens, antigen (Ag) 85A [23-25], Ag85B [25], Ag85C [25], MPT51 [26, 27], and DosR regulon-encoded proteins [28]. Here, we identified murine T-cell epitopes on MDP1 with a strategy using inbred mouse strains, gene gun immunization with expression plasmid DNA encoding MDP1, overlapping synthetic peptides spanning the entire mature MDP1 amino acid (aa) sequence, and major histocompatibility complex (MHC) binding peptide prediction algorithms.

\section{Materials and methods}

\subsection{Animals}

Inbred mouse strains, BALB/c, C57BL/6, and C3H/He, were purchased from Japan SLC (Hamamatsu, Japan). The mice were kept under specific pathogen-free conditions and fed autoclaved food and water ad libitum at the Institute for Experimental Animals of the Hamamatsu University School of Medicine. Two to three-month-old female mice were used in all experiments. Animal experiments were performed according to the Guidelines for Animal Experimentation, Hamamatsu University School of Medicine.

\subsection{Plasmid}

The DNA encoding MDP1 molecule was inserted between EcoRI and Xho I sites located downstream of cytomegalovirus immediate-early enhancer/promoter region of eukaryotic expression plasmid, pCI (Promega, Madison, WI, USA). The integrity of the nucleotide sequence was validated by automated DNA sequencing with ABI PRISM 310 genetic analyzer (Applied Biosystems, Foster City, CA, USA) using a dye primer cycle sequencing kit (Applied Biosystems). 


\subsection{Peptides}

Peptides spanning the entire MDP1 aa sequence of BCG (205 aa residues) were synthesized as 20-mer peptides overlapping by 10 residues, with the exception of P6 (p46-65) and the carboxyl-terminal P21 (p186-205) ([15], Fig. 1). MDP1 p23-31 and p46-60 peptides were synthesized by Hayashi kasei (Osaka, Japan). All peptides were dissolved in phosphate-buffered saline (PBS) at a concentration of $10 \mathrm{mg} \mathrm{ml}^{-1}$ and stored at $-80^{\circ} \mathrm{C}$ until use.

\subsection{Prediction of T-cell epitopes by MHC binding peptide prediction algorithms}

For the prediction of murine T-cell epitopes, following MHC binding peptide prediction algorithms were used through their web sites. These are, National Institutes of Health BioInformatics and Molecular Analysis Section (BIMAS) ([29], http://bimas.dcrt.nig.gov/cgi-bin/molbio/ken_parker_comboform), SYFPEITHI program ([30], http://www.syfpeithi.de/), and RANKPEP program ([31], http://bio.dfci.harvard.edu/Tools/rankpep.html).

\subsection{Immunization of mice}

For DNA immunization with Helios gene gun system (Bio-Rad Laboratories, Hercules, CA, USA), preparation of the cartridge of DNA-coated gold particle cartridge was followed to the manufacturer's instruction manual. Finally, $0.5 \mathrm{mg}$ of gold particles was coated with $1 \mu \mathrm{g}$ of plasmid DNA and the injection was carried out with $0.5 \mathrm{mg}$ gold per shot once. Mice were injected with $1 \mu \mathrm{g}$ of plasmid DNA four times at 1-week intervals. Mice were also immunized subcutaneously with $10^{6}$ CFU of BCG (Tokyo strain) twice at a 2-week interval.

\subsection{Preparation of splenocyte culture supernatants}

Spleen cells were harvested from mice. Recovered cells were cultured with RPMI medium 
supplemented with $10 \%$ fetal calf serum in 96 -well plates at $2 \times 10^{6}$ cells per well in the presence or absence of $5 \mu \mathrm{g} \mathrm{ml}^{-1}$ of each MDP1 peptide at $37^{\circ} \mathrm{C}$ with $5 \% \mathrm{CO}_{2}$ atmosphere. Supernatants were harvested $48 \mathrm{~h}$ later and stored at $-20^{\circ} \mathrm{C}$ until they were assayed. Concentration of IFN- $\gamma$ in the culture supernatants was determined by a sandwich enzyme-linked immunosorbent assay (ELISA)

\subsection{Quantification of IFN- $\gamma$ with ELISA}

The 96-well ELISA plates (EIA/RIA Plate A/2; Costar, Cambridge, MA) were coated with 2 $\mu \mathrm{g} \mathrm{ml}^{-1}$ of capture antibody (Ab) (anti-murine IFN- $\gamma$ monoclonal Ab [mAb] R4-6A2; BD Biosciences, San Jose, CA, USA) at $4^{\circ} \mathrm{C}$ overnight, washed with PBS supplemented with $0.05 \%$ Tween 20 (PBS-Tween), and blocked with Block One Blocking solution (Nakalai Tesque, Kyoto, Japan) at room temperature for $45 \mathrm{~min}$. After washed with PBS-Tween, the culture supernatants were added to the plates and the plates were incubated at $4^{\circ} \mathrm{C}$ overnight. After washed with PBS-Tween, $0.5 \mu \mathrm{g} \mathrm{ml}^{-1}$ of biotin-labeled anti-murine IFN- $\gamma$ mAb XMG1.2 (BD Biosciences) was added to the plates, and the plates were incubated for $1 \mathrm{~h}$ at room temperature. After washed with PBS-Tween, horseradish peroxidase-conjugated avidin (Bio-Rad Laboratories) was added and incubated for $30 \mathrm{~min}$ at room temperature. After washed, the plates were added with TMB one component HRP microwell substrate (BioFX laboratories, Owings Mills, MD, USA) to detect bound horseradish peroxidase-conjugated streptavidin. After $5 \mathrm{~min}$, the absorbance of each well was measured at $630 \mathrm{~nm}$ using an EZS-ABS Microplate Reader (Asahi Techno Glass Tokyo, Japan).

\subsection{Depletion of CD4+ or CD8+ T-cell subsets}

CD4+ or CD8+ T-cell subsets of peptide-reactive T cells were determined by depletion of CD4+ or CD8+ T cells, respectively. We used BD IMag system (BD Biosciences). Briefly, 
spleen cells was mixed thoroughly with anti-mouse CD4 particles-DM or anti-mouse CD8a particles-DM (BD Biosciences, $50 \mu \mathrm{l}$ particles for $10^{7}$ cells) and placed at $4^{\circ} \mathrm{C}$ for $30 \mathrm{~min}$. The labeled cells were placed on the BD IMagnet and incubated for 8 min. Supernatant was carefully removed. This supernatant contains the cell fraction which was depleted CD4+ or CD8+ T cells.

\subsection{MHC stabilization assay}

MHC stabilization assay is originally described in Ljunggren and colleagues [32]. RMA-S cells ([33], $10^{6}$ cells/well) were cultured at $26^{\circ} \mathrm{C}$ overnight and were then incubated for $1 \mathrm{~h}$ in the presence or absence of peptide $(10,50$, or $100 \mu \mathrm{M})$. The cells were then transferred to $37^{\circ} \mathrm{C}$ for $2 \mathrm{~h}$ and washed with FACS buffer, and cell surface expression of $\mathrm{H} 2-\mathrm{D}^{\mathrm{b}}$ molecules was detected by flow cytometry by usng phycoerythrin (PE)-conjugated mouse MAbs specific for $\mathrm{H} 2-\mathrm{K}^{\mathrm{d}} \mathrm{D}^{\mathrm{b}}$ (28-14-8; eBioscience, San Diego, CA, USA). The results were expressed as the mean fluorescence intensity (MFI) ratio, which was determined as follows: MFI ratio $=($ MFI observed in the presence of peptide at $37^{\circ} \mathrm{C}-\mathrm{MFI}$ observed in the absence of peptide at $\left.37^{\circ} \mathrm{C}\right) /(\mathrm{MFI}$ observed in the absence of peptide at $\left.26^{\circ} \mathrm{C}\right) \times 100(\%)$.

\subsection{Statistics}

Data from multiple experiments were expressed as the means \pm S.E.M. Data were analyzed with Student's unpaired t test. $\quad$ v value of 0.05 or less was considered significant.

\section{Results}

3.1. IFN- $\gamma$ production in response to overlapping synthetic peptides from MDP1 by splenocytes of pCI-MDP1 DNA-immune mice

Splenocytes from mice immunized with DNA vaccine encoding MDP1 (pCI-MDP1) were 
stimulated with the overlapping MDP1 peptides for $48 \mathrm{~h}$ and IFN- $\gamma$ concentration of culture supernatants was measured by ELISA. As shown in Fig. 2A, robust IFN- $\gamma$ production was observed in splenocytes from MDP1 DNA-immune C57BL/6 mice (H2 ${ }^{\mathrm{b}}$ haplotype) in the presence of peptides P3 (aa 21 to 40), P9 (aa 71 to 90), and P11 (aa 91 to 110). Similarly, significantly higher IFN- $\gamma$ production from splenocytes of MDP1 DNA-immune BALB/c $\left(H 2^{d}\right.$ haplotype) and $\mathrm{C} 3 \mathrm{H} / \mathrm{He}\left(\mathrm{H} 2^{\mathrm{k}}\right.$ haplotype) mice was observed in response to two peptides, $\mathrm{P} 5$ (aa 41 to 60), P6 (aa 46 to 65) and three peptides, P5 (aa 41 to 60), P13 (aa 111 to 130), and P16 (aa 141 to 160), respectively (Fig. 2B and C). In C3H/He mice, P11 (aa 91 to 110 ) and P12 (aa 101 to 120) could induce relatively high IFN- $\gamma$ production, but the value were not statistically significant.

In order to examine whether the same peptide induce IFN- $\gamma$ following natural mycobacterial infection, splenocytes from mice immunized with BCG were examined for IFN- $\gamma$ production in response to MDP1 peptides. Two peptides, P5 and P6, also induced significant IFN- $\gamma$ production from splenocytes of BCG-immune BALB/c mice (Fig. 2B), but the level of IFN- $\gamma$ produced in BCG-immune mice was lower than that in MDP1 DNA-immune mice. We were not able to detect significant IFN- $\gamma$ production from splenocytes of BCG-immune $\mathrm{C} 57 \mathrm{BL} / 6$ and $\mathrm{C} 3 \mathrm{H} / \mathrm{He}$ mice (Fig. 2A and C). In this experimental condition, DNA immunization with MDP1 DNA was superior to BCG vaccination in terms of IFN- $\gamma$ production level from splenocytes.

\section{2. $T$-cell subset analysis of $T$ cells by the depletion of $C D 4+$ or $C D 8+T$ cells}

Next, we examined which T-cell subsets responding to MDP1 peptides. CD4+ or CD8+ T cells were removed with magnetic beads and residual cells were stimulated with MDP1 peptides and resultant IFN- $\gamma$ production was compared. As shown in Fig. 3A, IFN- $\gamma$ production from splenocytes of C57BL/6 mice in response to P3 (aa 21 to 40) was significantly decreased by depleting CD8+ T-cell subset. In contrast, IFN- $\gamma$ production in response to P9 (aa 71 to 90) and P11 (aa 91 to 110) was decreased by depleting CD4+ T cells. These results indicate that P3 
contains CD8+ T-cell epitope, and P9 and P11 contain CD4+ T-cell epitopes. Intracellular IFN- $\gamma$ staining results showed that IFN- $\gamma$-producing CD8+, but not CD4+ T cells were observed in response to P3 in C57BL/6 mice. And IFN- $\gamma$-producing CD4+, but not CD8+ T cells were observed in response to $\mathrm{P} 9$ and $\mathrm{P} 11$ (data not shown). Since C57BL/6 mice have a deletion of H2-E $\alpha$ gene and do not express H2-E molecules on the cell surface [34], two CD4+ T-cell epitopes in these peptides are exclusively considered to be presented on $\mathrm{H} 2-\mathrm{A}^{\mathrm{b}}$.

In BALB/c mice, IFN- $\gamma$ production in the presence of P5 (aa 41 to 60) and P6 (aa 46 to 65) was significantly reduced by depleting CD4+ T cells. Similarly, IFN- $\gamma$ production in the presence of P5 (aa 41 to 60), P13 (aa 111 to 130), or P16 (aa 141 to 160) was significantly reduced by depleting $\mathrm{CD} 4+\mathrm{T}$ cells in $\mathrm{C} 3 \mathrm{H} / \mathrm{He}$ mice (Fig. 3B and $3 \mathrm{C}$ ). These results indicate that these peptide regions contain CD4+ T-cell epitopes.

\subsection{Identification of minimal T-cell epitopes in the responsive peptide regions of MDP1}

Generally, CD8+ T cells recognize peptides of 8 to 11 aa residues on MHC class I molecules and CD4+ T cells recognize peptides of 12 to 18 aa residues on MHC class II molecules. Several MHC binding peptide prediction algorithms are available on internet. We employed BIMAS and SYFPEITHI programs for prediction of CD8+ T-cell epitope(s) in P3 in C57BL/6 mice and RANKPEP program for CD4+ T-cell epitope(s) in P5 and P6 regions in BALB/c mice (Table 1). MDP1 p23-31 9mer peptide (AAVENVVDT) in P3 region showed the highest score (108) for H2-D $\mathrm{D}^{\mathrm{b}}$ binding in BIMAS program (Table 1). In BALB/c mice, RANKPEP algorithm predicted MDP1 p52-60 as the core motif of H2-A ${ }^{\mathrm{d}}$-restricted CD4+ T-cell epitope (Table 1). Since both P5 (p41-60) and P6 (p46-65) peptides let the immune splenocytes produce IFN- $\gamma$, we prepared overlapping 15mer peptide (p46-60) and examined the capacity to induce IFN- $\gamma$ production from immune splenocytes.

As shown in Fig. 4A, CD8+ T cells of MDP1 DNA-immune C57BL/6 mice produced 
significant amounts of IFN- $\gamma$ in response to MDP1 p23-31 peptide. Splenocytes of the immune mice in the absence of the peptide and splenocytes of naïve C57BL/6 mice with or without the peptide did not produce significant level of IFN- $\gamma$ (data not shown). Similarly, CD4+ T cells of MDP1 DNA-immune BALB/c mice produced significant amounts of IFN- $\gamma$ in response to MDP1 p46-60 peptide (Fig. 4B). Splenocytes of the immune mice in the absence of the peptide and splenocytes of naïve BALB/c mice with or without the peptide did not produce significant level of IFN- $\gamma$ (data not shown). These results indicate that MDP1 p23-31 is a minimal bona fide CD8+ T-cell epitope in C57BL/6 mice and MDP1 p46-60 is CD4+ T-cell epitope in BALB/c mice, respectively.

As for $\mathrm{C} 3 \mathrm{H} / \mathrm{He}$ mice, RANKPEP program predicted that MDP1 p41-60 contains MDP1 p46-54 peptide which showed the highest score (10.8) in MDP1 peptides presented on H2-A ${ }^{\mathrm{k}}$. However, the score was less than the peptide binding threshold value (14.2), suggesting no binding. The SYFPEITHI program, which has the prediction program for $\mathrm{H} 2-\mathrm{A}^{\mathrm{k}}$ and $\mathrm{E}^{\mathrm{k}}$, predicted MDP1 p44-58 15mer peptide as $\mathrm{H} 2-\mathrm{E}^{\mathrm{k}}$ binder with the highest score (24) in the program (Table 1). RANKPEP program also predicted three core 9 mer peptides restricted by $\mathrm{H} 2-\mathrm{E}^{\mathrm{k}}$, MDP1 p113-121, p116-124, and p121-129 in P13 (p111-130) region and two core peptides restricted by H2-E $\mathrm{E}^{\mathrm{k}}$, MDP1 p142-150 and p145-153 in P16 (p141-160) region, respectively (Table $1)$.

\subsection{Identification of an MHC class Ia restriction molecule for MDP1 p23-31 in C57BL/6 mice}

Since MDP1 p23-31 was found to be a CD8+ T-cell epitope for C57BL/6 mice, we examined MHC binding assay to determine $\mathrm{H} 2$ restriction molecule for the peptide. As shown in Fig. 5, The MFI ratio of PE-conjugated anti-H2- $\mathrm{D}^{\mathrm{b}} \mathrm{mAb}$ increased in the presence of $10 \mu \mathrm{M}$ of MDP1 p23-31 peptide. This value further increased up to $42.5 \%$ in the presence of $100 \mu \mathrm{M}$ of the peptide. This result confirmed that MDP1 p23-31 peptide does bind to H2-D ${ }^{b}$. 


\section{Discussion}

$\mathrm{T}$ cells play pivotal role in induction of protective immunity against intracellular pathogens such as Mtb $[6,7]$. The protective immunity induced by MDP1 immunization would be mainly attributable to T-cell responses evoked by the immunization. We here determined murine T-cell epitopes of MDP1, which would give the concrete basis of the protective immunity by MDP1 immunization. The peculiar immunogenic feature of MDP1 is DNA-dependent augmentation of antigenicity. MDP1 elicited protective immune responses when it was vaccinated to BALB/c and $\mathrm{C} 3 \mathrm{H} / \mathrm{He}$ mice with genomic DNA derived from $M$. tuberculosis [21]. Up-regulation of antigen-presenting cell functions induced by the interaction between MDP1 and CpG DNA was suggested in the protective immune responses [21]. CpG DNA is a key component of DNA vaccines for evoking significant immune responses against antigens. Therefore, we considered that DNA vaccination of MDP1 induce substantial immune responses, because produced MDP1 proteins may bind to CpG DNA in plasmid backbone and enhance the adjuvant effects.

In this study, we found at least seven T-cell epitope candidates peptides upon MDP1 DNA immunization. By contrast, only one peptide region (MDP1 p41-65) was found with M. bovis BCG vaccination (Fig. 2B). Several reasons for this difference would be speculated. First, MDP1 localizes in the cytoplasmic space, or is tightly attached to the cell wall of the live Mycobacterium. Non-secreted antigens like MDP1 would be difficult to be immunoreactive in the form of BCG vaccine. Second, BCG vaccine has been reported to be inefficient in terms of MHC class I antigen presentation. The fact may also cause the difference in the T-cell responses. Other possible explanation is that living mycobacteria have the mechanism to hide immunogenicity of MDP1, because strong immune response to MDP1 causes bactericidal host response.

In C57BL/6 mice, we found one CD8+ T-cell epitope, MDP1 p23-31 and two CD4+ T-cell 
epitopes, MDP1 p71-90 and MDP1 p91-110. MDP1 p23-31 (AAVENVVDT) was speculated to be presented on $\mathrm{H} 2-\mathrm{D}^{\mathrm{b}}$ with prediction algorithms and this was confirmed with MHC binding assay. Reported dominant peptide binding motif of $\mathrm{H} 2-\mathrm{D}^{\mathrm{b}}$ consists of asparagine at position5 (P5) and hydrophobic C-terminal residue such as isoleucine or leucine (P9 or P10) [35, 36]. P5 of MDP1 p23-31 is asparagine, but the C-terminal residue does not fit the motif. P5 (asparagine) and P10 (isoleucine) of MDP1 p23-32 fit the motif, suggesting that MDP1 p23-32 peptide also works as CD8+ T-cell epitope.

In BALB/c mice, MDP1 p46-60 was identified as H2-A ${ }^{\mathrm{d}}$-restricted CD4+ T-cell epitope. Since both P5 (p41-60) and P6 (p46-65) peptides, but not P7 (p51-70) peptide, let the immune splenocytes produce IFN- $\gamma$, we reasoned that the N-terminal aa residues (p46-50) are critical for the function. In $\mathrm{C} 3 \mathrm{H} / \mathrm{He}$ mice, at least three $\mathrm{CD} 4+\mathrm{T}$-cell epitopes were identified. RANKPEP or SYFPEITHI programs predicted P5 (p41-60), P13 (p111-130), and P16 (p141-160) bind to $\mathrm{H} 2-\mathrm{E}^{\mathrm{k}}$.

In conclusion, we identified murine T-cell epitopes of MDP1, an immunogenic major cellular mycobacterial protein causing protective immunity. We identified several CD4+ T-cell epitopes in three inbred mouse strains and one CD8+ T-cell epitope in C57BL/6 mice. Previously, we reported murine T-cell epitopes of MPT51, which is one of major secreted mycobacterial proteins at acute phase TB. MDP1 is a very abundant cellular protein and has been reported to be even up-regulated in dormant stage mycobacteria. Therefore, T-cell epitopes of MPT51 and MDP1 would be feasible for analysis of T-cell responses in different stage Mtb and for futureTB vaccine design.

\section{Acknowledgements}

This work was supported by grants-in-aid for scientific research from the Japanese Society for the Promotion of Science (grant 20590438 to T. N. and grant 20390125 to Y. K.), a 
grant-in-aid for the Centers of Excellence (COE) research program from the Ministry of Education, Culture, Sports, Science and Technology of Japan, and a grant-in-aid from the United States-Japan Cooperative Medical Science Program.

\section{References}

[1] World Health Organization. WHO Report 2007 Global tuberculosis control: surveillance, planning, financing. Geneva 2008. [Online.] http://www.who.intentity/tb/publications/global_report/2008/pdf/fullreport.pdf. Accessed 15 November 2008.

[2] Bloom BR, Fine PEM. The BCG experience: implications for future vaccines against tuberculosis. In: Tuberculosis: pathogenesis, protection, and control. Washington, DC: ASM Press; 1994. p. 531-57.

[3] Andersen P, Doherty TM. The success and failure of BCG - implications for a novel tuberculosis vaccine. Nature Rev Microbiol 2005;3:656-62.

[4] Sterne JAC, Rodrigues LC, Guedes IN. Does the efficacy of BCG decline with time since vaccination? Int J Tuberc Lung Dis 1998;2:200-7.

[5] Andersen P. Tuberculosis vaccines — an update. Nature Rev Microbiol 2007;5:484-7.

[6] Kaufmann SHE. How can immunology contribute to the control of tuberculosis? Nat Rev Immunol 2001;1:20-30.

[7] Kaufmann SHE. Immunity to intracellular bacteria. In: W. E. Paul editor. Fundamental Immunology, 5th edition. Philadelphia: Lippincott Williams \& Wilkins Publishers; 2003.p. $1229-61$.

[8] Kaufumann, SHE, Flynn JL. CD8 T cells in tuberculosis. In: Cole ST, Eisenach KD, McMurray DN, Jacobs Jr WR. editors. Tuberculosis and the Tubercle Bacillus. Washington, 
DC: ASM Press; 2005. p. 465-74.

[9] Andersen P, Doherty TM. TB subunit vaccines - putting the pieces together. Microbes Infect 2005;7:911-21.

[10] Sable SB, Karlra M, Verma I, Khuller GK. Tuberculosis subunit vaccine design: The conflict of antigenicity and immunogenicity. Clin Immunol 2007;122:239-51.

[11] Park H-D, Guinn KM, Harrell MI et al. Rv3133c/dosR is a transcription factor that mediates the hypoxic response of Mycobacterium tuberculosis. Mol Microbiol 2003;48:833-43.

[12] Karakousis RC, Yoshimatsu T, Lamichhane G et al. Dormancy phenotype displayed by extracellular Mycobacterium tuberculosis within artificial granulomas in mice. J Exp Med 2004;200:647-57.

[13] Matsumoto S, Yukitake H, Furugen M, Matsuo T, Mineta T, Yamada T. Identification of a novel DNA-binding protein from Mycobacterium bovis Bacillus Calmette-Guérin. Mirobiol Immunol 1999;43:1027-36.

[14] Lee BH, Murugasu-Oei B, Dick T. Upregulation of a histone-like protein in dormant Mycobacterium smegmatis. Mol Gen Genet 1998;260:475-9.

[15] Furugen M, Matsumoto S, Matsuo T, Matsumoto M, Yamada T. Identification of the mycobacterial DNA-binding protein 1 region which suppresses transcription in vitro. Microb Path 2001;30:129-38.

[16] Matsumoto S, Furugen M, Yukitake H, Yamada T. The gene encoding mycobacterial DNA-binding protein I (MDP I) transformed rapidly growing bacteria to slowly growing bacteria. FEMS Microbiol Lett 2000;182:297-301.

[17] Lewin A, Baus D, Kamal E, et al. The mycobacterial DNA-binding protein I (MDPI) from Mycobacterium bovis BCG influences various growth characteristics. BMC Microbiol 2008;8:91-102.

[18] Katsube T, Matsumoto S, Takatsuka M, et al. Control of cell wall assembly by a histone-like protein in Mycobacteria. J Bacteriol 2007;189:8241-9. 
[19] Aoki K, Matsumoto S, Hirayama Y, et al. Extracellular mycobacterial DNA-binding protein 1 participates in Mycobacterium-lung epithelial cell interaction through hyaluronic acid. J Biol Chem 2004;279:39798-806.

[20] Prabhakar S, Annapurna PS, Jain NK, Dey AB, Tyagi JS, Prasad HK. Identification of an immunogenic histone-like protein $\left(\mathrm{HLP}_{\mathrm{Mt}}\right)$ of Mycobacterium tuberculosis. Tuberc Lung Dis 1998;79:43-53.

[21] Matsumoto M, Matsumoto M, Umemori K, et al. DNA augments antigenicity of mycobacterial DNA-binding protein 1 confers protection against Mycobacterium tuberculosis infection in mice. J Immunol 2005;175:441-9.

[22] Yoshida A, Nagata T, Uchijima M, Higashi T, Koide Y. Advantage of gene gun-mediated over intramuscular inoculation of plasmid DNA vaccine in reproducible induction of specific immune responses. Vaccine 2000;18:1725-9.

[23] Denis O, Tanghe A, Palfliet K, et al. Vaccination with plasmid DNA encoding mycobacterial antigen $85 \mathrm{~A}$ stimulates a $\mathrm{CD} 4^{+}$and $\mathrm{CD} 8^{+} \mathrm{T}$-cell epitopic repertoire broader than that stimulated by Mycobacterium tuberculosis H37Rv infection. Infect Immun 1998;66:1527-33.

[24] Tanghe A. D'Souza S, Rosseels V, et al. Improved immunogenicity and protective efficacy of a tuberculosis DNA vaccine encoding Ag85 by protein boosting. Infect Immun $2001 ; 69: 3041-7$

[25] D’Souza S, Rosseels V, Romano M, et al. Mapping of murine Th1 helper T-cell epitopes of mycolyl transferases Ag85A, Ag85B, and Ag85C from Mycobacterium tuberculosis. Infect Immun 2003;71:483-93.

[26] Suzuki M, Aoshi T, Nagata T, Koide Y. Identification of murine H2-D ${ }^{d}$ - and $\mathrm{H} 2-\mathrm{A}^{\mathrm{b}}$-restricted T-cell epitopes on a novel protective antigen, MPT51, of Mycobacterium tuberculosis. Infect Immun 2004;72:3829-37.

[27] Aoshi T, Nagata T, Suzuki M et al. Identification of an HLA-A*0201-restricted T-cell 
epitope on MPT51 protein, a major secreted protein derived from Mycobacterium tuberculosis by MPT51 overlapping peptide screening. Infect Immun 2008;76:1565-71.

[28] Roupie V, Romano M, Zhang L, et al. Immunogenicity of eight dormancy regulon-encoded proteins of Mycobacterium tuberculosis in DNA-vaccinated and tuberculosis-infected mice. Infect Immun 2007;75:941-9.

[29] Parker KC, Bednarek MA, Coligan JE. Scheme for ranking potential HLA-A2 binding peptides based on independent binding of individual peptide side-chains. J Immunol 1994;152:163-175.

[30] Rammensee H-G, Bachmann J, Emmerich NPN, Bachor OA, Sevanović S. SYFPEITHI: database for MHC ligands and peptide motifs. Immunogenetics 1999;50:213-9.

[31] Reche PA, Glutting J-P, Zhang H, Reinherz EL. Enhancement to the RANKPEP resource for the prediction of peptide binding to MHC molecules using profiles. Immunogenetics 2004;56:405-19.

[32] Ljunggren H-G, Stam NJ, Öhlén C et al. Empty MHC class I molecules come out in the cold. Nature 1990;346:476-80.

[33] Ljunggren H-G, Kärre K. Host resistance directed selectively against H-2-deficient lymphoma variants. J Exp Med 1985;162:1745-59.

[34] Mathis DJ, Benoist C, Williams II VE, Kanter M, McDevitt HO. Several mechanisms can account for defective $E \alpha$ gene expression in different mouse haplotypes. Proc Natl Acad Sci USA $1983 ; 80: 273-7$.

[35] Rammensee H-G, Friede T, Stevanović S. MHC ligands and peptide motifs: first listing. Immunogenetics 1995;41:178-228.

[36] Margulies DH, McClusky J. The major histocompatibility complex and its encoded proteins. In: W. E. Paul editor. Fundamental Immunology, 5th edition. Philadelphia: Lippincott Williams \& Wilkins Publishers; 2003. p. 571-612. 


\section{Figure legends}

Fig. 1. Schematic representation of the 21 overlapping synthetic peptides from MDP1 of BCG. All peptides covering entire MDP1 of BCG (205 aa residues) were synthesized as 20-mer molecules overlapping by 10 amino acids with the neighboring peptides.

Fig. 2. IFN- $\gamma$ production from splenocytes stimulated with overlapping peptides of MDP1. Inbred mice [C57BL/6, (A), BALB/c (B)and $\mathrm{C} 3 \mathrm{H} / \mathrm{He}(\mathrm{C})]$ were immunized with plasmid DNA encoding MDP1 using gene gun four times at 1-week interval (filled bars) or with M. bovis BCG two times at a 2-week interval (hatched bars). The splenocytes $\left(2 \times 10^{6}\right)$ were stimulated with overlapping peptides $\left(5 \mu \mathrm{g} \mathrm{ml}^{-1}\right) 2$ weeks after the last immunization. Naïve mice (open bars) were used as controls. IFN- $\gamma$ concentration of supernatant was analyzed by sandwich ELISA 48 h later. The means \pm S.E.M. from three $(\mathrm{C} 57 \mathrm{BL} / 6, \mathrm{BALB} / \mathrm{c})$ or six $(\mathrm{C} 3 \mathrm{H} / \mathrm{He})$ mice are shown. Asterisks $(*)$ indicate $p<0.05$ compared with the value without peptide $(-)$ with Student's unpaired $t$ test.

Fig. 3. Analysis of T-cell subsets responsive to MDP1 peptides. Mice were immunized with MDP1 DNA on the same schedule as Fig. 2. Splenocytes were treated with magnetic beads specific for CD4 or CD8. Cells $\left(2 \times 10^{6}\right)$ of the negative fraction were stimulated with peptides $\left(5 \mu \mathrm{g} \mathrm{ml}^{-1}\right)$. Amounts of IFN- $\gamma$ in the supernatant were analyzed by sandwich ELISA $48 \mathrm{~h}$ later. The mean \pm S.E.M. of three mice are shown. $\quad{ }^{* *} p<0.01,{ }^{*} p<0.05$ (Student's unpaired $t$ test).

Fig. 4. IFN- $\gamma$ production from $\mathrm{T}$ cells in the presence of predicted peptides, MDP1 p23-31 and p46-60 peptides. C57BL/6 and BALB/c mice were immunized with MDP1 DNA and the immune splenocytes were treated with magnetic beads specific for CD4 or CD8 $\alpha$ and purified the 
negative fraction. Cells $\left(2 \times 10^{6}\right)$ of the fraction were stimulated with $5 \mu \mathrm{g} \mathrm{ml}^{-1}$ of MDP1 p23-31 and MDP1 p46-65. IFN- $\gamma$ in the culture supernatant was analyzed by sandwich ELISA $48 \mathrm{~h}$ later. The mean \pm S.E.M. of three mice are shown. Asterisks $\left(^{*}\right)$ indicate $p<0.05$ compared with the value without peptide (-) with Student's unpaired $t$ test.

Fig. 5. MHC binding assay of MDP1 p23-31 to H2-D ${ }^{b}$. The ability of MDP1 p23-31 for binding to $\mathrm{H} 2-\mathrm{D}^{\mathrm{b}}$ was measured by determining the stabilization of class I molecules on the surfaces of TAP2-deficient RMA-S. RMA-S cells $\left(10^{6}\right.$ cells/well $)$ were cultured at $26^{\circ} \mathrm{C}$ overnight and then were incubated for $1 \mathrm{~h}$ in the presence or absence of peptide $(10,50$ or 100 $\mu \mathrm{M})$. The cells were then transferred to $37^{\circ} \mathrm{C}$ for $2 \mathrm{~h}$ and washed with FACS buffer, and cell surface expression of $\mathrm{H} 2-\mathrm{D}^{\mathrm{b}}$ was detected by flow cytometry by using a phycoerythrin-conjugated $\mathrm{mAb}$ specific for $\mathrm{H} 2-\mathrm{K}^{\mathrm{d}} \mathrm{D}^{\mathrm{b}}$. The results were expressed as MFI ratio $\pm \mathrm{SD}$. 


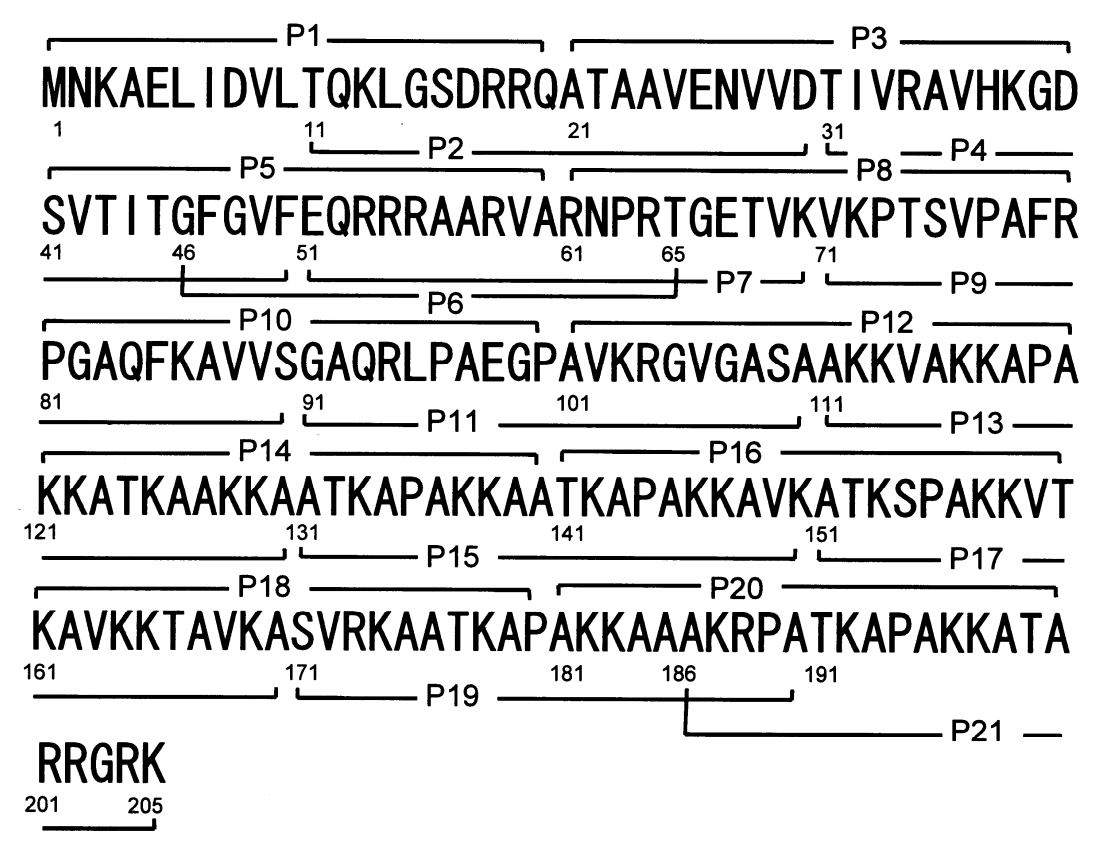

Fig. 1, Suzuki et al. 

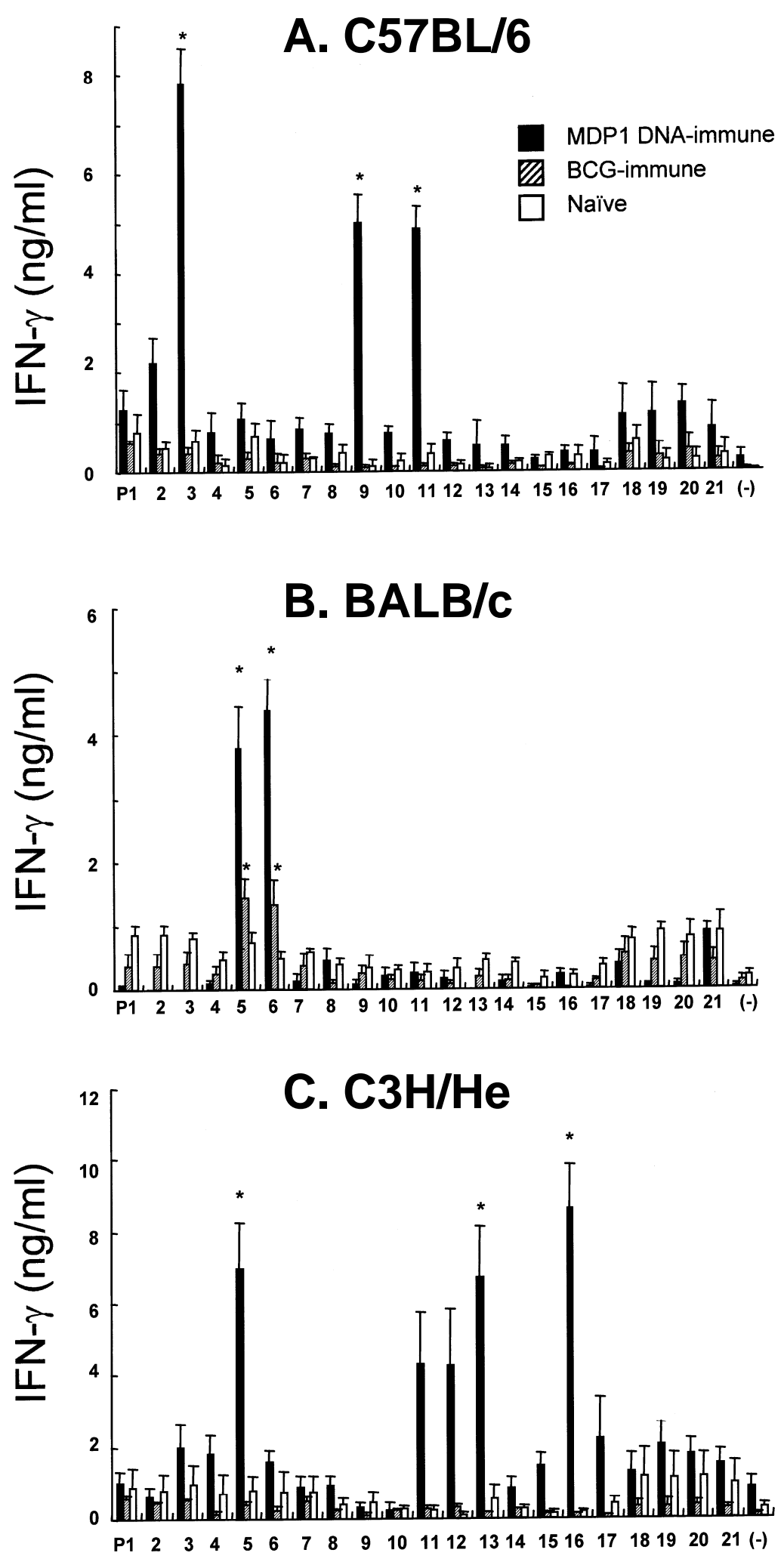

Fig. 2, Suzuki et al. 

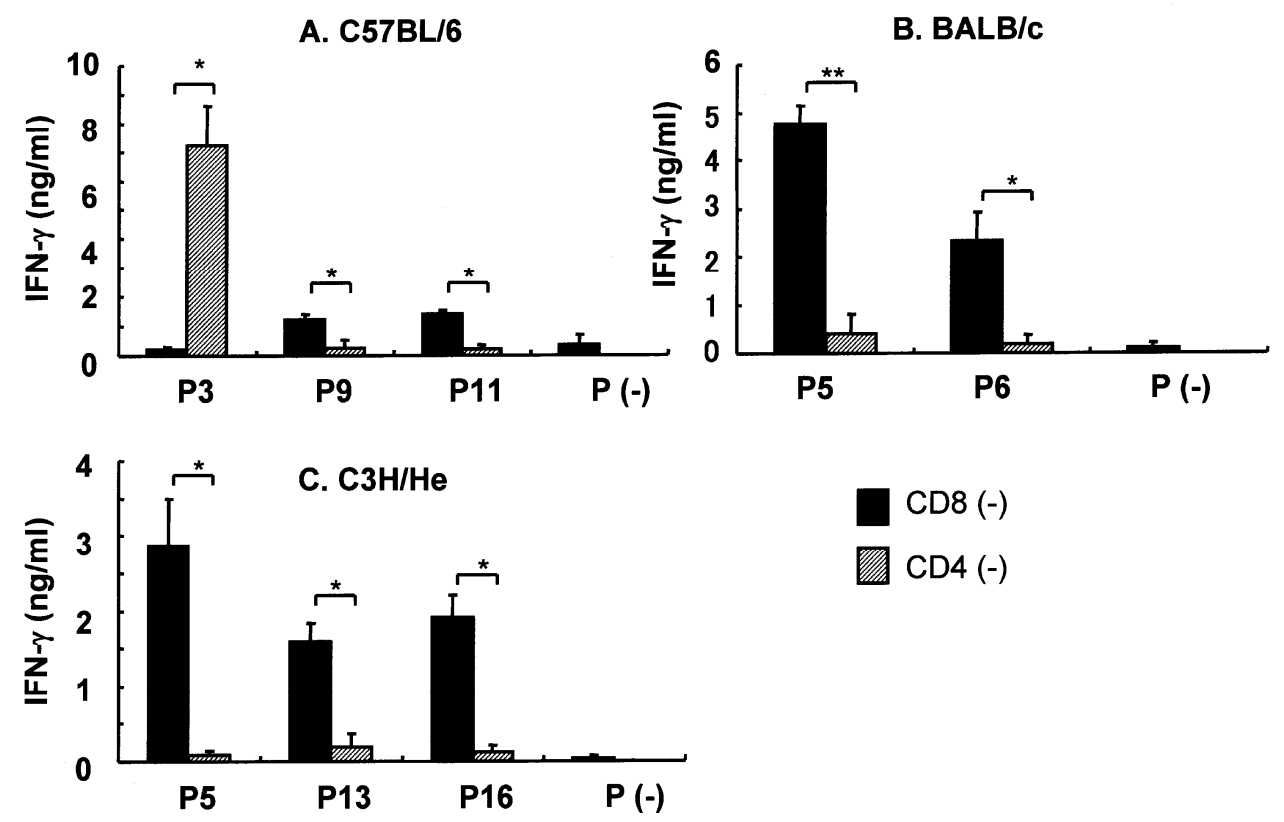

$\operatorname{CD8}(-)$
CD4 (-)

Fig. 3, Suzuki et al. 


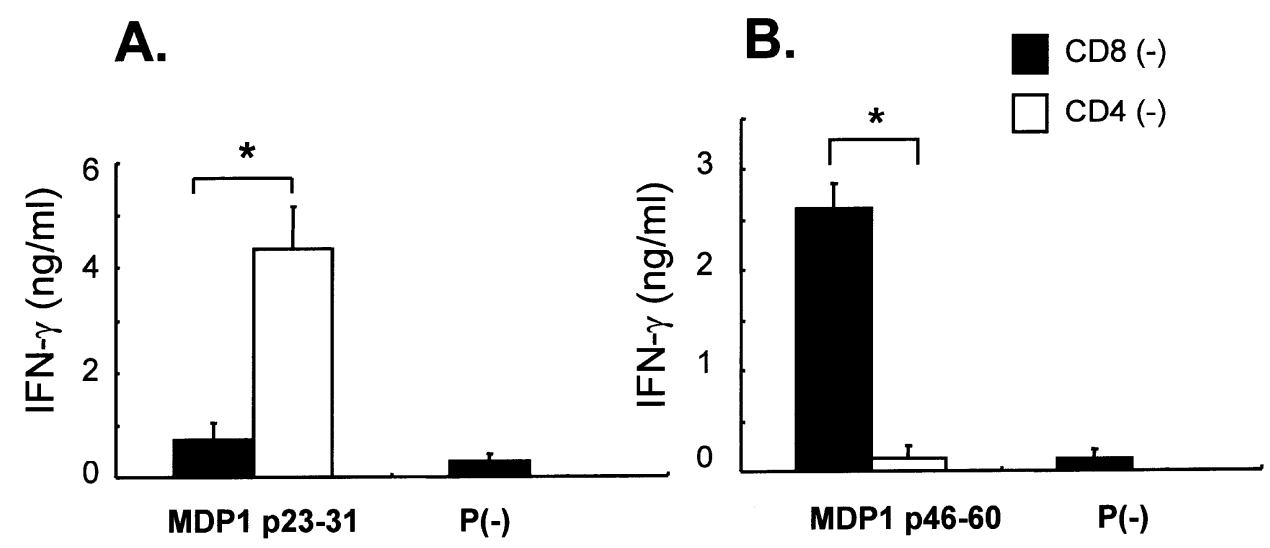

Fig. 4, Suzuki et al. 


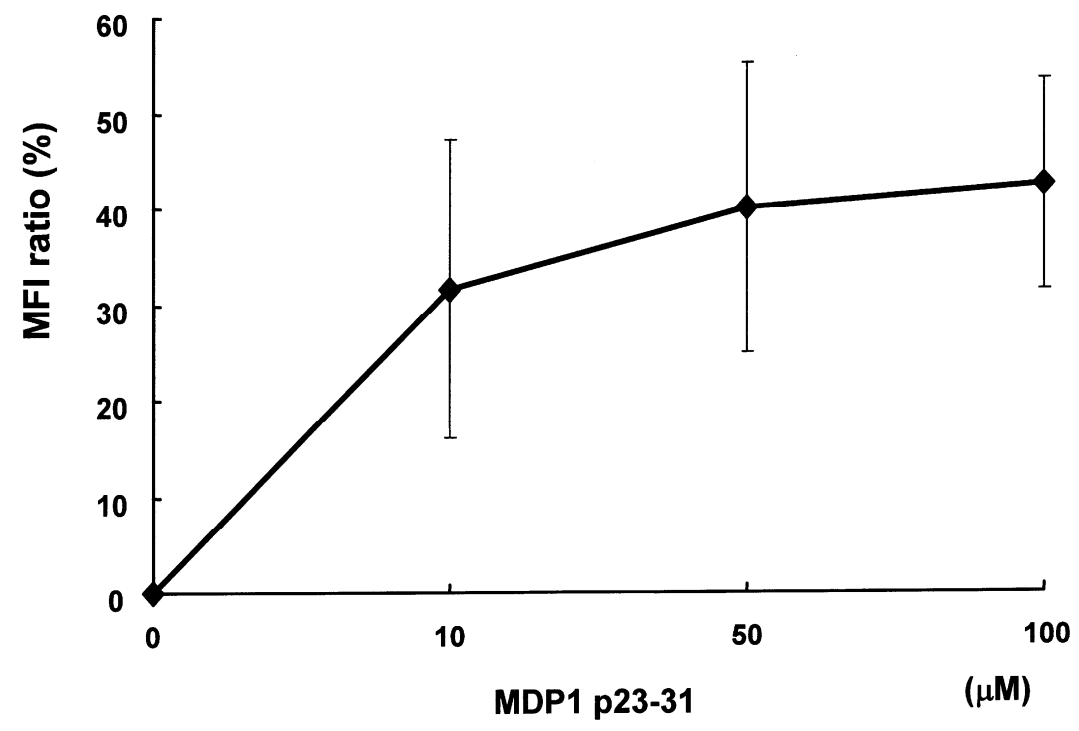

Fig. 5, Suzuki et al. 
TABLE 1. T-cell epitope candidates in MDP1 molecule

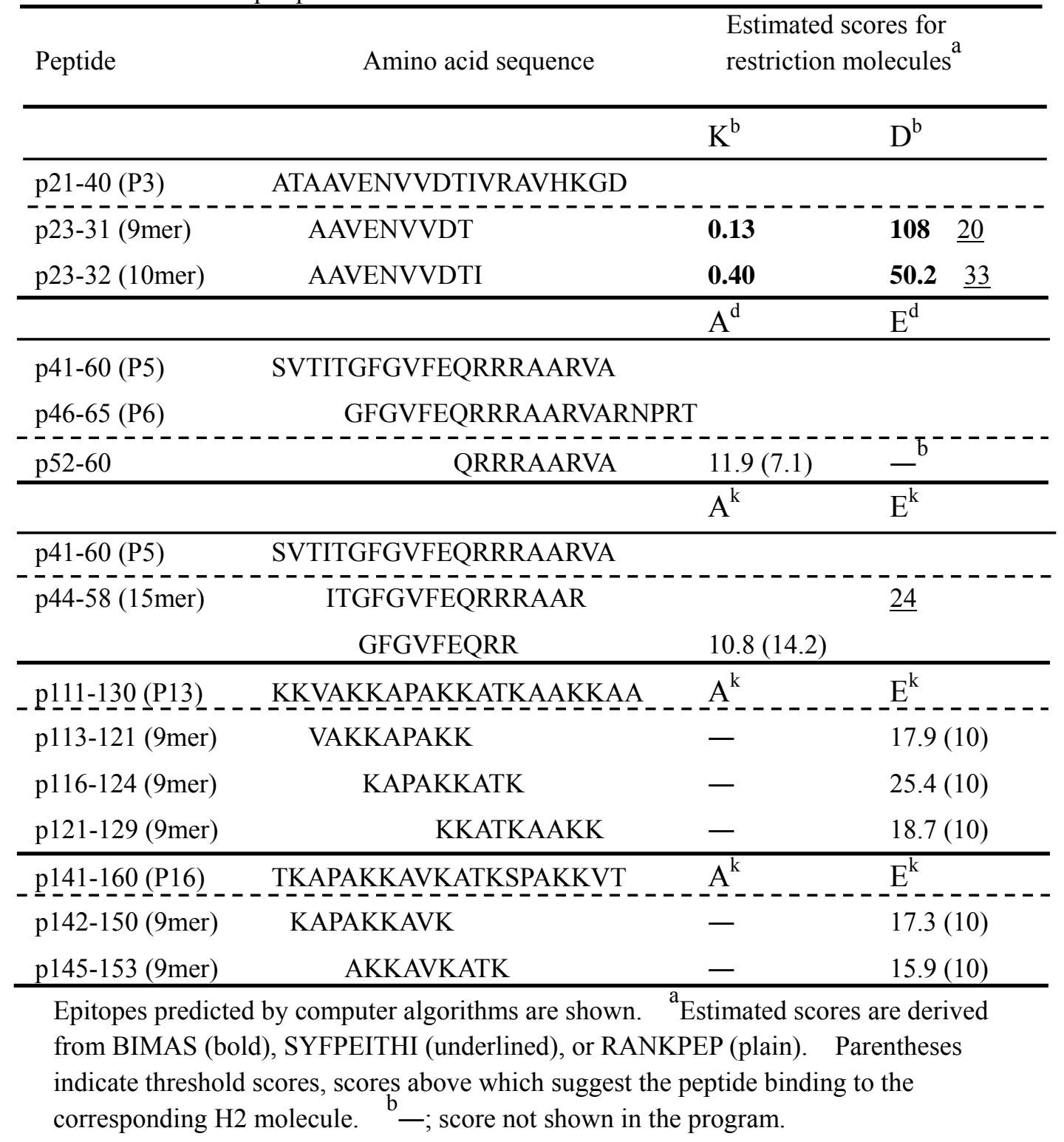

